\title{
Effect of bumetanide in capillary permeability pulmonary oedema
}

To determine if bumetanide, like furosemide, improves shunt through pulmonary vasoactivity, 20 dogs wish unilobar oleic acid pulmonary oedema were studied. Fractional perfusion and intrapulmonary shunt of the oedematous lobe were measured ar: baseline. $1 \frac{1}{2}$ hours after oleic acid infusion, 15 minutes later after either $0.1 \mathrm{mg} \cdot \mathrm{kg}^{-1}$ of bumetanide in ten dogs (Bumetanide Group) or without bumetanide in ten dogs (Control Group), and $2 \frac{1}{2}$ hours afier the oleic acid, the bumetanide being administered immediately after the It hours post-oleic acid measurements. Labar stunts for the Bumetanide Group were: $9.3 \pm 4.0$, $54.3 \pm 13.6,54.7 \pm 13.6,38.6 \pm 12.0$ per cent and for Conirols: $8.7 \pm 1.6,45.1 \pm 8.8,48.3 \pm 7.8,70.4 \pm 6.2$ per cent. Fractionat perfusions of the oedematows lobe were: $29.9 \pm 1$, $14.7 \pm 1.1,14.6 \pm 0.7,19.3 \pm 1.9$ per cent in the Bumetanide Group and $28.6 \pm 2.1,14.2 \pm 1.1,14.2 \pm 1.5$, and $9.9 \pm 1.1$ per cent in Controls. Oedema (wet to body weight ratio) was tess $(p<0.05)$ in the contralateral lobe $(2.5 \pm 0.2 \mathrm{vs} 2.9 \pm 0.3)$ and the aedematous lobe $(4.7 \pm 0.4$ vs $6.0 \pm 0.5)$ after bumetanideinduced diuresis. We conclude that bumetanide decreases shunt by decreasing oedema and not through pulmonary vasoactivity.

Bumetanide (3-n-butylamino-4-phenoxy-5-sulfamoylbenzoic acid) is a loop diuretic considered to have renal effects comparable to those of furosemide and is as effective in a dose of about two per cent of that of furosemide. ${ }^{1}$ This drug has been used successfully in treating congestive heart failure, ${ }^{2}$ nephrotic oedema ${ }^{3}$ and ascites. ${ }^{4}$ Our previous work with furosemide ${ }^{5}$ has shown that before the onset of diuresis or any change in the amount of oedema, improvement in gas exchange occurs. That this effect may result from pulmonary blood flow re-distribution away from flooded alveoli was suggested

\section{Key words}

I.UNG: pulmonary oedema, shunt; KIDNEY: diuretic; DIURETIC: bumetanide.

From the Department of Surgery, Faculty of Medicine, University of Manitoba, Winnipeg, Manitoba.

Address correspondence ro: Dr. J. Ali, Department of Surgery, Health Sciences Centre, 700 William Avenue, Winnipeg, Manitoba, R3E 0Z3. from a study of furosemide in unilobar low pressure pulmorary oedema. ${ }^{6}$ This mechanism was further confirmed by our examination of the effect of furosemide on the pressure-flow relationship of the pulmonary vasculature utilizing the isolated perfused canine lobe.

Low pressurc pulmonary oedema, secondary to pulmonary capillary endothelial injury accounts for major mortality and morbidity in critical care units. ${ }^{8}$ A lesion similar to that found in human low pressure pulmonary oedema can be produced by oleic acid infusion in the dog. ${ }^{9}$ This pulmonary lesion in the laboratory as well as in clinical studies is usually non-homogeneous with the more dependent areas of the lung being more affected by having a higher percentage of flooded alveoli. ${ }^{10.11}$ Drugs such as furosemide have produced improvement in gas exchange in these oedematous lungs before reducing the amount of oedema by redistributing blood flow away from flooded alveolar units. ${ }^{6}$

Although furosemide and bumetanide are considered to have similar renal effects it has not been firmly established whether bumetanide cemonstrates effects similar to furosemide on the gas exchange abnormality found in low pressure pulmonary oedema. The present study was aimed at determining whether bumctanide demonstrates any beneficial effects on gas exchange in oleic acid pulmonary oedema and whether these effects are related to pulmonary vasoactivity, as has been demonstrated with furosemide,

\section{Methods}

Twenty supine previously healthy mongrel dogs weighing between 18.5 and $23.5 \mathrm{~kg}$, initially anaesthetized with $30 \mathrm{mg} \cdot \mathrm{kg}^{-1}$ thiopentone IV and maintained with boluses of $1.5 \mathrm{mg} \cdot \mathrm{kg}^{-1}$ of this drug were mechanically ventilated with 100 per cent oxygen on a constant volume respirator (Harvard 607) using a tidal volume of $20 \mathrm{mg} \cdot \mathrm{kg}^{-1}$ and a respiratory rate of approximately 15 per minute. Polyethylene catheters were inserted in a femoral artery and vein and a Swan-Ganz catheter was inserted in the pulmonary artery through an exposed external jugular vein. The chest was opened through a median sternotomy after which nurmal transpulmonary pressure at end expiration was maintained by the application of a positive end expiratory pressure of $4 \mathrm{~cm} \mathrm{H}_{2} \mathrm{O}$. A Foley catheter 
was inserted into the bladder by suprapubic cystotomy. A specially designed bell-tipped polyethylene catheter $0.25 \mathrm{~mm}$ thick and $1.5 \mathrm{~mm}$ in internal diameter was secured into the left lower lobe pulmonary vein by a purse string suture. This catheter was used for sumpling lobar pulmonary venous blood. In order to avoid streaming of blood during pulmonary venous sampling blood was withdrawn very slowly while the catheter tip was manually agitated within the lumen of the vein in a direction perpendicular to the flow of blood. ${ }^{12}$ Lower lobe shunt and total intrapulmonary shunt were determined as described previously ${ }^{6}$ from oxygen contents of systemic arterial, mixed venous and pulmonary venous blood as determined by a carbon monoxide scrubbing technique. ${ }^{13}$

Total pulmonary blood flow and left lower lobe pulmonary blood flow were determined from calibrared electromagnetic flow probes placed around the main pulmonary artery and the left lower lobe pulmonary artery. The fraction of the cardiac output perfusing the left lower lobe was determined by representing the left lower lobe pulmonary artery flow as a percentage of the total pulmonary artery flow, 14,15

After control measurements the pulmonary artery catheter was introduced into the left lower lobe pulmonary artery where it was manually held with the balloon inflated while $0.03 \mathrm{ml} \cdot \mathrm{kg}^{-1}$ of oleic acid was infused, producing left lower lobe capillary leak pulmonary oedema. ${ }^{6}$ Previous experience with this model $^{6}$ has shown that the oleic acid injury is essentially confined to the left lower lobe since shunt and lung water in the remaining lung do not increase.

\section{Measurements}

Measurements made were total intrapulmonary and left lower lobe shunts, fractional perfusion to the left lower lobe, systemic arterial pressure from the femoral artery catheter connected to a Statham P23AC pressure transducer, pulmonary artery and wedge pressures from the pulmonary artery catheter connected to a Statham P23BB pressure transducer and airway opening pressure from a Statham PMS pressure transducer connected to the endotracheal tube. All pressure signals were displayed on a Gould multichannel recorder. Urine output was measured every 15 minutes after oleic acid infusion.

\section{protocol}

The above measurements were made at the following times:

(a) At baseline after all the lines were inserted and the animals were stable;

(b) $1 \frac{1}{2}$ hours after oleic acid infusion;

(c) 15 minutes after randomly, either $0.1 \mathrm{mg} \cdot \mathrm{kg}^{-1}$ bumetanide was given intravenously to ten dogs (Bumet- anide Group) or an equivalent volume of normal saline was given intravenously to the other ten dogs (Control Group); and

(d) $2 \frac{1}{2}$ hours after the oleic acid infusion.

The bumetanide or saline was administered immediately after the $1 \frac{1}{2}$ hour post-oleic acid measurements. Al the end of the experiment which was approximately one hour after bumetanide or $2 \frac{1}{2}$ hours after oleic acid infusion, the animal was heparinized with 200 international units of sodjum heparin $/ \mathrm{kg}$ body weight and exsanguinated through the arterial line. The lungs were then excised and divided into lobes which were weighed (wet weight). From these measurements the wet weight to body weight ratio of the lobes were determined as a measure of the degree of pulmonary oedema.

\section{Results}

Data are expressed as means \pm standard deviation and were analyzed by analysis of variance followed by the application of Tukey's multiple range test, a p value $\leq$ 0.05 being regarded as statistically significant.

Analysis of the pulmonary and systemic hacmodynamic data failed to reveal any statistically significant difference between the two groups of animaIs (Table). In particular, there was no statistically significant difference in the pulmonary artery wedge pressure between the bumetanide and control groups. As anticipated, there was a statistically significant increase in urine output in the bumetanide treated animals at one hour after the bumetanide infusion. The urine output was $14.7 \pm 5.0 \mathrm{ml}$ in the first 15 minutes and $154 \pm 96 \mathrm{ml}$ for the one hour post-bumetanide. Corresponding urine outputs for the Control Group were: $9.5 \pm 8.0 \mathrm{ml}$ in the first 15 minutes and $45.0 \pm 14 \mathrm{ml}$ for the one hour post-saline. There was no statistically significant difference in urine output between the two groups for the first 15 minutes after saline or bumetanide administration.

Lobar shunt of the oleic acid treated lobes increased to the same extent in both groups of animals at $1 \frac{1}{2}$ hours after the oleic acid infusion, this increase being from $9.3 \pm 4.0$ per cent to $54.3 \pm 13.6$ per cent in the Bumetanide Group and $8.7 \pm 1.6$ per cent to $45.1 \pm 8.8$ per cent in the Control Group (Figure 1). At 15 minutes after bumetanide or sline infusions there were still no differences in the shunts of the left lower lobes being: $34.7 \pm 13.6$ per cent in the Bumetanide Group and $48.3 \pm 7.8$ per cent in Control Group. However, by one hour after bumetanide infusion there was a statistically significant fall in the shunt of the oedematous lobe to $38.6 \pm 12.0$ per cent compared to the Control Group which showed further deterioration in shunt up to $70.4 \pm 6.2$ per cent at one hour after saline infusion (Figure 1). The total intrapulmonary shunt followed the same pattern in that at $1 \frac{1}{2}$ hours after 
TABLE Haemodynaraics and total intrapulmonary shunt

\begin{tabular}{|c|c|c|c|c|c|}
\hline & $\overline{P A}(m m H g)$ & $\overrightarrow{P W}(m m H g)$ & $\overline{P A F}\left(L \cdot m i n^{-1}\right)$ & $\overline{B P}(m m H g)$ & Shunt $(\%)$ \\
\hline \multicolumn{6}{|c|}{ Bumetanide group $(\mathrm{n}=10)$} \\
\hline Baseline & $11.6 \pm 4.1$ & $7.5 \pm 3.6$ & $3.3 \pm 0.4$ & $129 \pm 24$ & $9.7 \pm 2.0$ \\
\hline It hrs, after OA & $12.3 \pm 5.3$ & $7.5 \pm 3.8$ & $3.1 \pm 0.4$ & $121 \pm 28$ & $19.2 \pm 3.1^{*}$ \\
\hline $15 \mathrm{~min}$. later & $12.6 \pm 5.4$ & $7.5 \pm 4.0$ & $3.0 \pm 0.4$ & $119 \pm 21$ & $19.5 \pm 2.8$ \\
\hline $2 \mathrm{~b}$ hrs. after OA & $11.9 \pm 4.9$ & $7.1 \pm 3.4$ & $2.9 \pm 0.3$ & $117 \pm 19$ & $15.4 \pm 2.5 * \dagger$ \\
\hline \multicolumn{6}{|c|}{ Control group $(n=10)$} \\
\hline Baseline & $12.9 \pm 2.9$ & $7.4 \pm 3.0$ & $2.9 \pm 0.3$ & $123 \pm 17$ & $9.6 \pm 2.0$ \\
\hline It hrs. after $O A$ & $13.1 \pm 2.3$ & $7.3 \pm 1.9$ & $2.7 \pm 0.3$ & $116 \pm 22$ & $18.5 \pm 4.8^{*}$ \\
\hline 15 min. later & $13.6 \pm 2.2$ & $7.2 \pm 2.2$ & $2.6 \pm 0.3$ & $112 \pm 19$ & $21.2 \pm 4.2$ \\
\hline $2 \frac{1}{\mathrm{~h} r \mathrm{~s}}$ after $\mathrm{OA}$ & $12.3 \pm 1.7$ & $6.7 \pm 1.8$ & $2.5 \pm 0.4$ & $107 \pm 9$ & $25.7 \pm 3.8^{*}$ \\
\hline
\end{tabular}

$\overline{\mathrm{PA}}$ - Mean pulmonary artery pressure.

$\overline{\mathrm{PW}}$ - Mean pulmonary capillary wedge pressure.

$\overline{\text { PAF }}$ - Mean pulmonary artery low.

$\overline{\mathrm{BP}}$ - Męan systemic arterial pressure.

$\widehat{\mathrm{OA}}-$ Olcic acid

$*-p<0.05$ compared to previous value.

$\dagger-p<0.05$ compared to control.

oleic acid infusion there was a statistically significant increase in total intrapulmonary shunt. Whereas the control group continued to increase total intrapulmonary shunt to $25.7 \pm 3.8$ per cent at $2 \frac{1}{2}$ hours after oleic acid, the bumetanide treated animals showed a statistically significant but small drop in total intrapulmonary shunt to $15.4 \pm 2.5$ per cent (Table).

Fractional perfusion to the oedematous lobe decreased significantly in both groups of animals at $1 \frac{1}{2}$ hours after oleic acid infusion from $29.9 \pm 1.8$ per cent to $14.7 \pm 1.1$ per cent in the Bumetanide Group and $28.6 \pm 2.1$ per cent to $14.2 \pm 1.1$ per cent in the Control Group (Figure 2). At 15 minutes after bumetanide or saline infusion there was no change in the fractional perfusion to the lower lobes of the bumetanide or saline treated lobes. However, whereas the bumctanide treated lobes increased their fractional perfusion at one hour after bumetanide infusion, the saline treated lobes continued to decrease their fractional perfusion at $2 \frac{1}{2}$ hours after oleic acid infusion, the values decreasing from $14.2 \pm 1.4$ per cent to $9.9 \pm 1.1$ per cent compared to a fractional perfusion of $19.3 \pm 1.9$ per cent in the bumetanide treated animals (Figure 2).

Comparison of the amount of oedema as measured by the wet to body weight ratio of the right and left lower lobes of the lungs show that the left lower lobe had a greater amount of oedema when compared to the right lower lobe in both groups of animals. Ilowever, both the right lower lobe and left lower lobe of the bumetanide treated group had less oedema than the corresponding lobes of the control group. The wet to body weight ratios of the left lower lobes were: $4.7 \pm 0.4$ with bumetanide and $6.0 \pm 0.5$ with saline. For the right lower lobes these

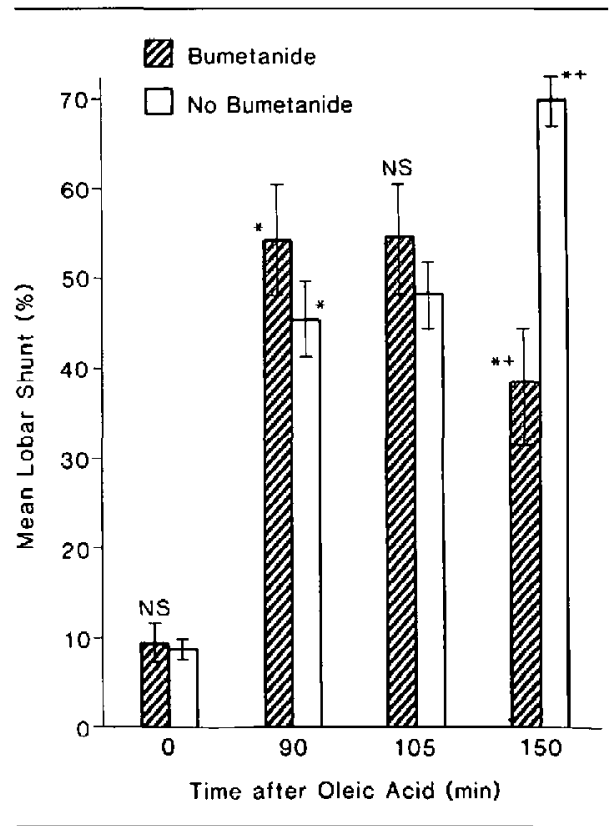

FIGURE 1 Lobar shunts with and without bumetanide; ${ }^{*} p<0.05$ compared to immediately preceding value; $\dagger_{p}<0.05$ compared to other group; NS - no significant difference between groups or from preceding value. Shunt of the oedematous lobe increased at it hours after olecic acid. Lobar shunt continued to deteriorate in the control group but improved one hour after bumetanide. 


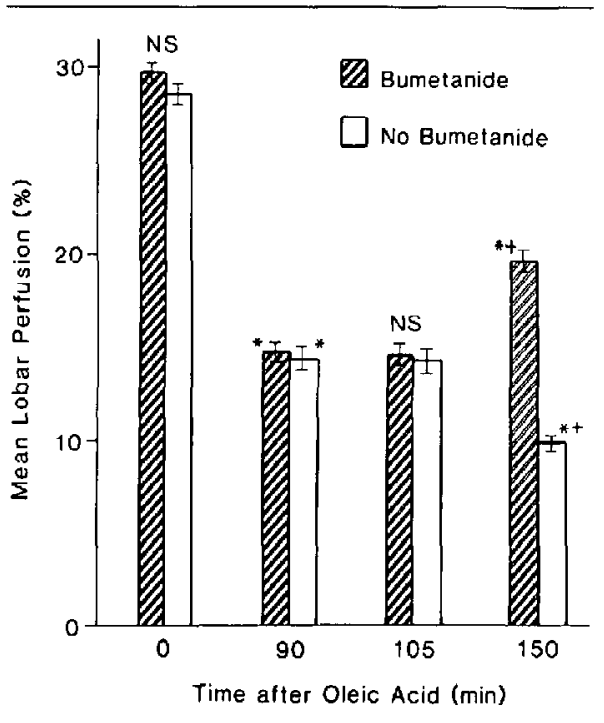

FIGURE 2 Fractional perfusion to the oedematous lobes; ${ }^{*} p<0.05$ compared to immediately preceding value; $\dagger_{\mathrm{p}}<0.05$ compared to other group; NS - no significant difference between groups or from preceding value. There was a 50 per cent drop in fractional perfusion to the oedematous lobe in both groups of animals at $1 \frac{1}{2}$ hours after oleic acid. Fifteen minutes after bumetanide there was no difference between the two groups. At 21 hours after oleic acid the Bumetanide Group showed a statislically significant increase in fractional perfusion while the control group demonstrated a continued decrease in fractional perfusion to the oedematous lobe.

ratios were: $2.5 \pm 0.2$ with Bumetanide and $2.9 \pm 0.3$ for Controls.

\section{Discussion}

The beneficial effects on gas exchange in pulmonary oedema following diuresis have generally been regarded as being secondary to a decrease in central blood volume and a decrease in capillary hydrostatic pressure with a resultant decrease in pulmonary oedema. ${ }^{16} \mathrm{~A}$ decrease in central blood volume may be associated with a decrease in cardiac output which itself has been shown to be associated with a decrease in intrapulmonary shunt in low pressure pulmonary oedema. ${ }^{17,18}$ Our previous studies have shown that furosemide possesses vasoactive properties which may be responsible for the early improvement in gas exchange before the clearing of pulmonary oedema. ${ }^{5-7}$ It would appear from our present data that although bumetanide improves shunt in capillary leak pulmonary oedema, this improvement is not immediate as evidenced by the failure to detect any improvement in shunt or changes in fractional lobar perfusion within 15 minutes of bumetanide infusion in this study. The difference in fractional perfusion to the oedematous lobe in the bumetanide treated animals as opposed to the control animals at $2 \frac{1}{2}$ hours after oleic acid oedema is more likely due to a mobilization of the oedema rather than a direct effect on the pulmonary vasculature, since any effect on the pulmonary vasculature should be evidenced within the 15 minute period as demonstrated with furosemide in the previous studies. This conclusion is based on our previous studies demonstrating that up to 50 per cent of the decreased perfusion resulting from oleic acid pulmonary oedema arises from the mechanical effects of the oedema itself ${ }^{14}$ and that mobilization of the oedema would be expected to relieve this mechanical cause of the decreased perfusion.

The present data suggest that improvement in gas exchange in the presence of capillary leak pulmonary oedema with bumetanide is related to the diuresis and a significant decrease in the amount of oedema. However, the decrease in oedema cannot be readily explained by a decrease in central blood volume resulting in a decrease in pulmonary artery wedge pressure since in our present study the pulmonary artery wedge pressure was the same in the bumetanide treated animals as it was in the saline treated animals. It is possible that the pulmonary artery wedge pressure may not accurately reflect pulmonary capillary hydrostatic pressure which may have decreased following bumetanide diuresis with a resultant decrease in oedema. Other mechanisms not elucidated in our present study include a possible increase in pulmonary capillary oncotic pressure that will enhance oedema mobilization following diuresis. Alternatively sodium and chloride flux across cellular membranes have been shown to be affected by diuretics. ${ }^{19-21}$ Such actions could conceivably alter transcapillary fluid flux. Other agents such as $\beta$-agonists ${ }^{22}$ have been shown to affect sodium and water transpor across alveolar epithelium. It is conceivable that bumetanide may act at this alveolar epithelial level in enhancing oedema mobilization.

The failure to demonstrate a pulmonary vascular effect of bumetanide similar to that of furosemide may be related to the difference in biochemical formula of these two drugs in that bumetanide has a phenoxy group side chain in contrast to the halogen atom in furosemide. This difference in chemical structure has been implicated in explaining the difference in renal excretion of phosphate by bumetanide as opposed to furosemide ${ }^{1}$ and could conceivably explain the difference in pulmonary vasoactivity between these two loop diuretics. 


\section{References}

1 Carriere $S$, Dandavino R. Bumetanide, a new loop diuretic. Clin Pharmacol Ther 1976; 20: 424-38.

2 Oleson EH, Sigurd B, Steiness E, Leth A. Bumetanide, a new potent diuretic. A clinical evaluation in congestive heart failure. Acta Med Scand 1973; 193: 119-31.

3 Lau K, DeFranzo R, Morrison C, Rascoff I, Goldherg $M$, Agus ZS. Effectiveness of bumetanide in nephrotic syndrome: a double blind crossover study with furosemide. J Clin Pharmacol 1976; 16: 489-97

4 Ring-Larsen $H$. Bumletanide in the treatment of hepatic ascites. A short and long term study. Acta Med Scand 1974; 195: 411-4.

5 Ali $J$, Chernecki $W$, Wood $L D H$. Effect of furoscmide in canine low pressure pulmonary oedema. J Clin Invest 1979; 64: 1494-1504.

6 Ali $J$, Wood $L D H$. Pulmonary vascular effects of furosemide on gas exchange in pulmonary oedema. J Appl Physiol 1984; 57: 160-7.

7 Ali J, Unruh H, Skoog C, Goldberg HS. The effect of lung oedema on pulmonary vasoactivity of furosemide. J Surg Res 1983; 35: 383-90.

8 Murray JF. Mechanisms of acute respiratory failure. Conference Report. Am Rev Respir Dis 1977; 115: 1071-9.

9 Ashbaugh $D C$, Uzawa $T$. Respiratory and hemodynamic changes after injection of free fatty acids. J Surg Res 1968; 18: 417-21.

10 Huchon $G J$, Hopewell $P$. Murray $J F$. Interactions between permeability and hydrostatic pressure in perfused dogs' lungs. J Appl Physiol 1981; 50: 905-11.

II Malo J, Ali J, Wood LDH. How does positive end expiratory pressure reduce intrapulmonary shunt in caninc pulmonary oedema? J Appl Physiol 1984; 57: 1002-10.

12 Fisher $C J$, Wood $L D H$. Effect of lobar acid aspiration on pulmonary perfusion and gas exchange. I Appl Physiol 1980; 59: 150-6.

13 Kirk $B W$, Raber $M B$. A practical apparatus for rapid determination of blood oxygen content. J Apl Physiol 1973; 34: 724-5.

14 Ali J, Wood $\mathrm{LDH}$. Factors aftecting perfusion distribution in canine oleic acid pulmonary ocdema. J Apl Physio] 1986; 60: 1498-1503.

15 Bredenberg $C E$, Webb WR. The effect of unilateral PEEP on the accumulation of lung water. Ann Surg 1979; 189: 433-8.

16 Kiely J, Kelly DT, Tuylor DR, Pitt B. The role of furosemide in the treatment of left ventricular dysfunction associated with acute myocardial infarction. Circulation 1973; 48: $581-7$

17 Ali J, Wood $L D H$. Does increased pulmonary blood flow redistribute towards edematous lung units? J Surg Res $1983 ; 35 ; 188-94$.
18 Lynch JP, Mhyre JG, Dantzker DR. Influence of cardiac output on intrapulmonary shunt. J Appl Physiol 1980; 59; 150-56.

19 Dunn MJ. Diuretics and red blood cell transport of cations. $I n$ : Modern Diuretic Therapy in the Treatment of Cardiovascular and Renal Disease, edited by AJ Lant and GM Wilson. Amsterdam: Excerpta Med 1973.

20 Kreye VA, Bauer PK, Villhauer I. Evidence of furosemide-sensitive active chloride transport in vascular smooth muscle. Eur J Pharmacol 1981; 73: 91-5.

21 McGahan MC, Yorio T, Bentley PI. The mode of action of bumetanide: inhibition of chloride transport across the amphibian cornea. J. Pharmacol Exp Ther 1977; 203: 97-102.

22 Crandall ED, Heming TA, Palombo RL, Goodman BE. Effects of terbutaline on sodium transport in isolated perfused rat lung. J Appl Physiol 1986; 60: 289-94.

\section{Résumé}

Afin de déterminer si la bumétanide, comme la furosémide. améliore le shunt à travers une vasoactivité pulmonaire, 20 chiens dont un labe pulmonaire est rendu oedématié par l'acide oléique ont été étudiés. La perfusion régionale et le shunt intrapulmonaire du lobe oedématié ont été mesurés aux temps suivants: contrôle, une heure et demie après la perfusion d'acide oléique, 15 minutes plus tard après injection soit de $0.1 \mathrm{mg} \cdot \mathrm{kg}^{-1}$ de bumétanide chez dix chiens (groupe Bumétanide) ou sans injection de bumétanide chez dix chiens (Groupe contrôle), et deux heures et demie après l'acide oléique. La bumétanide étant administrée immédiatemem après les mesures faites une heure et demie après l' injection d'acide olétque. Les shunts labaires pour le groupe bamétanide étaient: $9.3 \pm 4.0 .54 .3 \pm$ $13.6,54.7 \pm 13.6,38.6 \pm 12.0$ pour cent et pour le groupe contrôle: $8.7 \pm 1.6,45 . J \pm 8.8,48.3 \pm 7.8,70.4 \pm 6.2$ pour cent. La perfusion régionale des lobes oedematiés étaient de: $29.9 \pm 1,14.7 \pm 1.1,14.6 \pm 0.7,19.3 \pm 1.9$ pour cent pour le groupe bumétanide er de $28.6 \pm 2.1 .14 .2 \pm 1.1 .14 .2 \pm$ 1.4, et $9.9 \pm 1.1$ pour cent pour le groupe contrôle. L'oedème (rapport poids frais sur poids corporel) était moindre $(p<0.05)$ dans le lobe contralatéral $(2.5 \pm 0.2$ vs $2.9 \pm 0.3)$ er pour le lobe oedématie $(4.7 \pm 0.4$ us $6.0 \pm 0.5)$ après diurèse induite par la bumétanide. On conclup que la bumétanide diminue le shunt en diminuant l'oedème et non par son action sur la vasaactivité pulmonaire. 